\title{
Correlation between exposure to fine particulate matter and hypertensive disorders of pregnancy in Shanghai, China
}

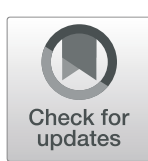

\author{
Xiujuan Su, Yan Zhao, Yingying Yang and Jing Hua ${ }^{*}$ (D)
}

\begin{abstract}
Background: Association between fine particulate matter $\left(\mathrm{PM}_{2.5}\right)$ and hypertensive disorders of pregnancy (HDP) is inconsistent and appears to change in each trimester. We aim to investigate the association of exposure to ambient $\mathrm{PM}_{2.5}$ in early pregnancy with HDP.

Methods: A retrospective cohort study was performed among 8776 women with singleton pregnancy who attended the antenatal clinic before 20 gestational weeks in a tertiary women's hospital during 2014-2015. Land use regression models were used to predict individual levels of $\mathrm{PM}_{2.5}$ exposure.

Results: The average $\mathrm{PM}_{2.5}$ concentration during the first 20 gestational weeks ranged from 28.6 to $74.8 \mathrm{\mu g} \mathrm{m}^{-3}$ [median, $51.4 \mathrm{\mu g} \mathrm{m}^{-3}$; interquartile range, $47.3-57.8 \mathrm{\mu g} \mathrm{m}^{-3}$ ]. A total of 440 (5.0\%) women was diagnosed with HDP. The restricted cubic spline showed a positive exposure-response relationship between the $\mathrm{PM}_{2.5}$ concentration and risk of HDP. We observed an association between $\mathrm{PM}_{2.5}$ exposure during the first trimester with $\mathrm{HDP}$ ( $\mathrm{RR}=3.89$ per $10 \mathrm{\mu g} \mathrm{m}^{-3}, 95 \% \mathrm{Cl}: 1.45-10.43$ ), but not during the second trimester ( $\mathrm{RR}=0.71$ per $10 \mu \mathrm{g} \mathrm{m}^{-3}, 95 \% \mathrm{Cl}: 0.40-1.27$ ). Compared with their counterparts, nulliparous women who were exposed to high levels of $\mathrm{PM}_{2.5}$ in the index pregnancy had a higher risk of developing HDP [the relative excess risk due to interaction was 0.92 (0.46-1.38)].

Conclusion: Our findings suggest that $\mathrm{PM}_{2.5}$ exposure during the first trimester is associated with the development of HDP. The effect estimate is more obvious for nulliparous women than multiparous women.
\end{abstract}

Keywords: Fine particulate matter $\left(\mathrm{PM}_{2.5}\right)$, Hypertensive disorders of pregnancy, Hypertension, Parity, Relative excess risk due to interaction

\section{Background}

Hypertensive disorders of pregnancy (HDP), including gestational hypertension, preeclampsia, and eclampsia, exert substantial adverse effects on both maternal and foetal health $[1,2]$. It complicates up to $10 \%$ pregnancies $[3,4]$ and ranks as the second leading causes of maternal mortality in China [5]. Despite the serious consequences, the biological mechanisms underlying HDP remain unclear.

\footnotetext{
*Correspondence: jin_huash@163.com

Department of Women \& Children's Health Care, Shanghai First Maternity and Infant Hospital, Tongji University School of Medicine, No.2699, West Gaoke Road, Shanghai 200040, China
}

Fine particulate matter (median aerodynamic diameter $\leq 2.5 \mu \mathrm{m} ; \mathrm{PM}_{2.5}$ ), has been proposed to be associated with the incidence of hypertension in the general population [6-8]. $\mathrm{PM}_{2.5}$ generally has been associated with increased risks of cardiovascular diseases within hours to days of exposure in susceptible individuals [9]. Due to cardiovascular changes that occur as part of a normal pregnancy, pregnant women might be more vulnerable to the adverse effects of $\mathrm{PM}_{2.5}$, while its association with HDP is inconsistent and appears to change in each trimester [10-13]. Two systematic reviews, both of which were published in 2014, reported contradictory effect

(c) The Author(s). 2020 Open Access This article is licensed under a Creative Commons Attribution 4.0 International License, which permits use, sharing, adaptation, distribution and reproduction in any medium or format, as long as you give appropriate credit to the original author(s) and the source, provide a link to the Creative Commons licence, and indicate if changes were made. The images or other third party material in this article are included in the article's Creative Commons licence, unless indicated otherwise in a credit line to the material. If material is not included in the article's Creative Commons licence and your intended use is not permitted by statutory regulation or exceeds the permitted use, you will need to obtain permission directly from the copyright holder. To view a copy of this licence, visit http://creativecommons.org/licenses/by/4.0/ The Creative Commons Public Domain Dedication waiver (http://creativecommons.org/publicdomain/zero/1.0/) applies to the data made available in this article, unless otherwise stated in a credit line to the data. 
estimates between $\mathrm{HDP}$ and $\mathrm{PM}_{2.5}$ exposure during pregnancy $[14,15]$. A case-control study of 298 predominantly Hispanic women reported an association between $\mathrm{PM}_{2.5}$ exposure during the first trimester, but not the second trimester, and an increased risk of HDP among non-obese women [16]. Additionally, two other studies based on the registry data suggested an association between second-trimester exposure to $\mathrm{PM}_{2.5}$ and an increased risk of HDP [12, 17]. The inconsistent findings may be due to the differences in $\mathrm{PM}_{2.5}$ concentrations and the ethnicity of the population [13]. We are not aware of any studies that have evaluated the association between HDP and exposure to a higher concentration of $\mathrm{PM}_{2.5}$ than the WHO interim target- 1 of $\mathrm{PM}_{2.5}$ $\left(35 \mu \mathrm{g} \mathrm{m}^{-3}\right)$ [18].

In this retrospective cohort study, we sought to investigate the association between exposure to ambient $\mathrm{PM}_{2.5}$ in early pregnancy with HDP. We hypothesize that the risk of HDP increases as the $\mathrm{PM}_{2.5}$ concentration increases and varies according to the trimester of pregnancy.

\section{Methods}

\section{Study population}

We performed a hospital-based, retrospective cohort study among pregnant women with a singleton pregnancy, who were attending the antenatal clinic from January 2014 to December 2015 in Shanghai First Maternity and Infant Hospital in Shanghai, China. Since HDP is generally clinically diagnosed beginning at 20 gestational weeks and we did not have detailed information on the diagnosis date of HDP, women with an initial visit at a gestational week before 20 weeks were included in the study $(n=21,944)$. Details of the study population have also been described previously [19].

All women were invited to provide personal sociodemographic and health information at the initial antenatal appointment, including age at conception, residence address, employment status (employed or unemployed), health insurance (with or without), parity (nulliparous or multiparous), height (in centimetres), and weight before pregnancy (in kilograms). The pre-conception body mass index (BMI) was calculated by dividing the weight (in kilograms) by the height (in metres squared) and was categorized into three groups according to WHO cut-off points recommendations for Asian women [20]: underweight (BMI $<18.5 \mathrm{~kg} \mathrm{~m}^{-2}$ ), normal weight (BMI 18.5$\left.23 \mathrm{~kg} \mathrm{~m}^{-2}\right)$, overweight $\left(23-27.5 \mathrm{~kg} \mathrm{~m}^{-2}\right)$ or obese $\left(\mathrm{BMI} \geq 27.5 \mathrm{~kg} \mathrm{~m}^{-2}\right)$. Gestational age was assessed based on the date of the last menstrual period and the results of the early ultrasound. We also asked women if either of their parents had a history of chronic diseases, including heart diseases, diabetes, hypertension, and kidney diseases.
Women with missing or implausible pre-pregnancy weight or weight at initial clinic $(<34$ or $>150 \mathrm{~kg})$, or height $(<100 \mathrm{~cm})$ were excluded $(n=13,157)$. In addition, women with a diagnosis of chronic hypertension before pregnancy were also excluded from the study $(n=11)$. Finally, 8776 women were included in the study. We also analysed the difference of basic characteristic between included women and excluded women. Compared to the excluded women, the included women were more likely to have government-sponsored health care insurance. Other characteristics, including age, gestational age, sex of foetus, season of conception are comparable between the two groups (Table S1 in additional file).

\section{Fine particulate matter $\left(\mathrm{PM}_{2.5}\right)$ exposure assessment}

A land-use regression (LUR) model, a feasible way to describe the relationship between land use and $\mathrm{PM}_{2.5}$ pollution level, was used to predict outdoor $\mathrm{PM}_{2.5}$ levels at the residential address of each participating woman [21, 22]. The dependent variable in LUR model was the mean values of $\mathrm{PM}_{2.5}$ concentration collected by Shanghai Environmental Monitor Centre at 35 monitoring locations. The independent variables included longitude, distance from monitors to the ocean, highway intensity, waterbody area, and industrial land area. Forward stepwise multiple regression method was employed to fit the model. The adjusted $\mathrm{R}$ squared value for the model was 0.88 . This method was described in more detail by $\mathrm{C}$ Liu et al. 2016 [21]. A map showing the locations of participants relative to the monitors is provided in our previous article [23]. We defined a priori three exposure windows of $\mathrm{PM}_{2.5}$ according to the birthdate and gestation weeks in this study, including the first trimester $(0$ 12 gestational weeks), early second trimester (13-20 gestational weeks) and the period before a potential diagnosis of HDP (0-20 gestational weeks). We logtransformed the $\mathrm{PM}_{2.5}$ concentrations measured in the different gestational periods to improve normality and variance homogeneity [24]. Concentrations of $\mathrm{PM}_{2.5}$ were analysed as continuous or categorical variables according to the interquartile range (IQR) in the study.

\section{Outcome}

The outcome of the study was HDP. Women with an onset of hypertension (systolic blood pressure and/or diastolic blood pressure $\geq 140 / 90 \mathrm{mmHg}$ ) after 20 weeks of gestation were diagnosed with HDP during the study period (2014-2015). Information on HDP was identified from electronic medical records and the maternal hospital discharge summary by an information engineer. Two trained researchers double-checked the information by referring to scanned medical records. In our main analysis, we combined gestational hypertension, pre- 
eclampsia, eclampsia, and hemolytic anemia, elevated liver function and low platelet count syndrome (HELLP syndrome) as a whole group.

\section{Statistical analysis}

Descriptive statistics for participant characteristics are presented as the means [standard deviations (SD)] for continuous variables and frequencies with percentages for categorical variables. The distribution of $\mathrm{PM}_{2.5} \mathrm{ex}$ posure was presented as medians and IQR during each of the specified time windows.

Firstly, we assessed the possibility of a nonlinear relationship between $\mathrm{PM}_{2.5}$ exposure and the risk of HDP using Poisson regression model with restricted cubic splines (RCS) with 3 knots (the 25th, 50th, 75th percentile) for $\mathrm{PM}_{2.5}$ [25]. The 50th percentile of the $\mathrm{PM}_{2.5}$ was treated as reference. As the results did not indicate a nonlinear association between $\mathrm{PM}_{2.5}$ and risk of HDP, the relative risks (RR) and 95\% confidence interval (CI) for $\mathrm{PM}_{2.5}$ exposure during the index gestational period and the risk of HDP was estimated through Poisson regression analysis without RCS by PROC GENMOD in SAS 9.4 in the main analysis. The RR per $10 \mu \mathrm{g} \mathrm{m}^{-3}$ or per IQR and $95 \% \mathrm{CI}$ for an increase in the $\mathrm{PM}_{2.5}$ concentration during a specific gestational period were obtained. Covariates in the adjusted multivariable analysis were identified a priori based on association with both $\mathrm{PM}_{2.5}$ and HDP. We included maternal age, parity, parental history of chronic diseases, health insurance, sex of foetus, and season of conception [17, 26, 27]. Considering the different pathophysiology for subtypes of hypertension, we reran the analyses for gestational hypertension and preeclampsia separately.

In a sensitivity analysis, we performed exploratory analysis to explore other covariates that are known to or might modify the association between $\mathrm{PM}_{2.5}$ exposure during the first trimester and the risk of HDP on the additive and multiplicative scales, including maternal age (<35 or $\geq 35$ years), pre-conception BMI (underweight, normal weight, overweight or obese), parental history of hypertension (yes, no), season of conception (spring and winter, summer and autumn), and parity (nulliparous or multiparous). The multiplicative interaction was evaluated by including the interaction index in the models. The additive interaction was evaluated by the relative excess risk due to the interaction (RERI) [28]. If an additive interaction was not observed, the $95 \%$ CI of the RERI would include zero.

All statistical tests were two-sided and used an $\alpha$ level of 0.05 . Statistical analyses were performed using SAS 9.4 (SAS Institute Inc., Cary, NC, USA). Figures were prepared with Stata/SE15 (StataCorp, College Station, TX, USA).

\section{Results}

Of the 8776 women in the study population, 440 (5.01\%) women were diagnosed with HDP. Table 1 shows the demographic characteristics of the participants. At baseline, the mean age of the participants was $30.1(\mathrm{SD}=3.6)$ years at conception, 7117 (81.1\%) were nulliparous, 1659 (18.9\%) were multiparous, 1436 (16.4\%) were overweight, $226(2.6 \%)$ were obese, and $1408(16.0 \%)$ were underweight. Notably, 3136 (35.7\%) women became pregnant in the spring, 1778 (20.3\%) in the summer, 1541 (17.6\%) in the autumn and $2321(26.5 \%)$ in the winter. Greater than $30 \%$ of women $(n=2749)$ reported a history of chronic diseases in either of their parents. Compared to normotensive women, women with HDP tended to be overweight or obese and were more likely to be nulliparous or have a parental history of chronic diseases.

Table 2 shows the average concentration to $\mathrm{PM}_{2.5}$ exposure among the study participants in different exposure periods. The $\mathrm{PM}_{2.5}$ concentration measured throughout the 20-week period ranged from 28.6 to $74.8 \mu \mathrm{g} \mathrm{m}^{-3}$ (median, $51.4 \mu \mathrm{g} \mathrm{m}^{-3}$; IQR: $47.3-57.8 \mu \mathrm{g}$ $\mathrm{m}^{-3}$ ). Median (IQR) $\mathrm{PM}_{2.5}$ concentrations recorded in the first and second trimester of pregnancy were $54.6 \mu \mathrm{g}$ $\mathrm{m}^{-3}$ (IQR: $46.5-60.1 \mu \mathrm{g} \mathrm{m}^{-3}$ ) and $52.0 \mu \mathrm{g} \mathrm{m}^{-3}$ (IQR: $44.3-56.3 \mu \mathrm{g} \mathrm{m}^{-3}$ ), respectively. The $\mathrm{PM}_{2.5}$ concentration is higher among women with HDP compared to women without HDP in first trimester and the whole 0 20 gestational weeks $(P<0.05)$.

The restricted cubic spline of the exposure-response relationship between $\mathrm{PM}_{2.5}$ exposure at different gestational periods and the risk of HDP was illustrated in Fig. 1). After adjusting for maternal age, parity, parental history of chronical diseases, health insurance, sex of foetus, and season of conception, the RR for HDP increased monotonically following an increase in the $\mathrm{PM}_{2.5}$ concentration in a positive exposure-response relationship pattern for each exposure period examined, which indicated a linear association between them.

We observed an increased risk of HDP associated with $\mathrm{PM}_{2.5}$ exposure during the first trimester, but not during the second trimester and or the entire 0 20 gestational week period (Table 3). The adjusted RR was 3.89 per $10 \mu \mathrm{g} \mathrm{m}^{-3}$ (95\% CI: $1.45-10.43$ ) for the first trimester, 0.61 per $10 \mathrm{\mu g} \mathrm{m}^{-3}$ (95\% CI, $0.33-$ 1.11) for the second trimester, and 0.71 per $10 \mu \mathrm{g} \mathrm{m}^{-3}$ (95\% CI, 0.40-1.27) for the entire $0-20$ gestational week period.

When the exposure was categorized into four groups, participants exposed to the second, third and fourth quartiles of $\mathrm{PM}_{2.5}$ had RR of 1.30 (95\% CI: 0.93-1.82), 1.66 (95\% CI: $1.11-2.48)$ and 1.67 (95\% CI: $1.10-2.53$ ), respectively, for HDP compared with participants exposed to the first quartile of ambient $\mathrm{PM}_{2.5}$ 
Table 1 Basic Characteristics of the participants $(n=8776)$

\begin{tabular}{|c|c|c|c|c|}
\hline Characteristics & Total $(n=8776)$ & No HDP $(n=8336)$ & $\operatorname{HDP}(n=440)$ & $P$ value \\
\hline Gestational age at enrollment (days) & $104.0 \pm 8.7$ & $104.0 \pm 8.6$ & $104.3 \pm 8.9$ & 0.46 \\
\hline Maternal age at enrollment (year) & $30.2 \pm 3.6$ & $30.2 \pm 3.6$ & $30.4 \pm 3.7$ & 0.14 \\
\hline Maternal height (centimeters) & $161.7 \pm 4.8$ & $161.7 \pm 4.8$ & $161.7 \pm 5.0$ & 0.85 \\
\hline Maternal weight before pregnancy $(\mathrm{kg})$ & $54.8 \pm 7.8$ & $54.6 \pm 7.5$ & $59.8 \pm 10.9$ & $<0.01$ \\
\hline \multicolumn{5}{|l|}{ Pre - conception BMI $\left(\mathrm{kg} \mathrm{m}^{-2}\right)$} \\
\hline Underweight $(<18.5)$ & $1408(16.0)$ & $1372(16.5)$ & $36(8.2)$ & \\
\hline Normal (18.5-23) & $5706(65.0)$ & $5486(73.6)$ & $220(50.0)$ & \\
\hline Overweight (23-27.5) & $1436(16.4)$ & $1298(15.6)$ & $138(31.4)$ & \\
\hline Obesity ( $\geq 27.5)$ & $226(2.6)$ & $180(2.2)$ & $46(10.5)$ & $<0.01$ \\
\hline \multicolumn{5}{|l|}{ Season of conception } \\
\hline Spring & $3136(35.7)$ & $2951(35.4)$ & $185(42.1)$ & \\
\hline Summer & $1778(20.3)$ & $1695(20.3)$ & $83(18.9)$ & \\
\hline Autumn & $1541(17.6)$ & $1492(17.9)$ & $49(11.1)$ & \\
\hline Winter & $2321(26.5)$ & $2198(26.4)$ & $123(27.9)$ & $<0.01$ \\
\hline \multicolumn{5}{|l|}{ Parity } \\
\hline Nulliparous & $7117(81.1)$ & $6735(80.8)$ & $382(86.8)$ & \\
\hline Multiparous & $1659(18.9)$ & $1601(19.2)$ & $58(13.2)$ & $<0.01$ \\
\hline \multicolumn{5}{|l|}{ Sex of foetus } \\
\hline Male & $4510(51.4)$ & $4284(51.4)$ & $226(51.4)$ & \\
\hline Female & $4266(48.6)$ & $4085(48.6)$ & $214(48.6)$ & 0.99 \\
\hline \multicolumn{5}{|l|}{ Parental history of chronic diseases } \\
\hline No & $6027(68.7)$ & $5777(69.3)$ & $250(56.8)$ & \\
\hline Yes & $2749(31.3)$ & $2559(30.7)$ & $190(43.2)$ & $<0.01$ \\
\hline \multicolumn{5}{|l|}{ Prenatal care insurance type } \\
\hline Government-sponsored & $6900(78.6)$ & $6535(78.4)$ & $365(83.0)$ & \\
\hline Self-pay & $1876(21.4)$ & $1801(21.6)$ & $75(17.0)$ & 0.02 \\
\hline
\end{tabular}

concentrations. The $P$-value for the Cochran-Armitage trend test was $<0.01$. The association pattern of $\mathrm{PM}_{2.5}$ with preeclampsia or gestational hypertension was similar to the main analysis (data available upon request).

No multiplicative or additive interactions were observed between maternal age, pre-conception BMI, parental history of hypertension, season of delivery and $\mathrm{PM}_{2.5}$ concentration in the first trimester on the risk of HDP (Table 4). An additive interaction and multiplicative interaction between $\mathrm{PM}_{2.5}$ exposure and parity were detected, which indicated that parity modified the effect of $\mathrm{PM}_{2.5}$ exposure on the risk of HDP.

\section{Discussion}

We estimate the association between $\mathrm{PM}_{2.5}$ exposure during specific gestational periods and risk of HDP in a retrospective hospital-based cohort study. Based on the results, pregnant women might be at higher risk of developing $\mathrm{HDP}$ following exposure to $\mathrm{PM}_{2.5}$ in the first trimester. Furthermore, the association shows a positive exposure-response pattern and is modified by parity.

We observed a prevalence of 5\% for HDP in this cohort, which is consistent with findings that reported a prevalence of $4.2 \%$ for HDP in China [29]. Our results were supported by a study which suggested that

Table 2 Summary of estimated PM2.5 concentration $\left(\mu \mathrm{g} \mathrm{m}^{-3}\right)$

\begin{tabular}{|c|c|c|c|c|}
\hline \multirow[t]{2}{*}{ Gestational period } & \multicolumn{3}{|c|}{ Median (Q1 - Q3) } & \multirow{2}{*}{$\begin{array}{l}P \\
\text { value }\end{array}$} \\
\hline & Total & No HDP & HDP & \\
\hline 0-12 gestational weeks & $54.6(46.5-60.1)$ & $54.4(46.3-60.0)$ & $57.2(50.1-60.6)$ & $<0.01$ \\
\hline 13-20 gestational weeks & $52.0(44.3-56.3)$ & $52.0(44.3-56.3)$ & $52.1(44.2-56.5)$ & 0.68 \\
\hline 0-20 gestational weeks & $51.4(47.3-57.8)$ & $51.3(47.3-57.8)$ & $54.1(47.8-58.3)$ & 0.03 \\
\hline
\end{tabular}



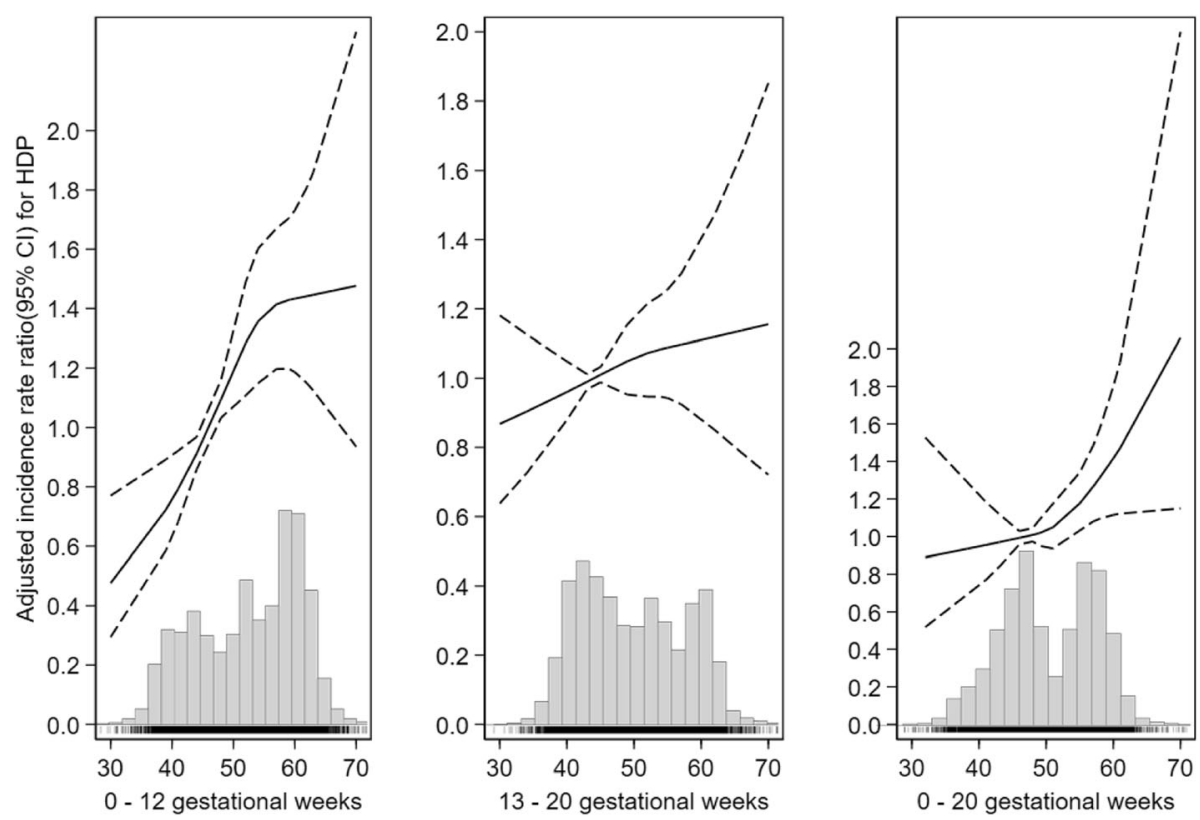

Fine particulate matter concentration ( $\mu \mathrm{g} \mathrm{m-3)}$

Fig. 1 The curve shows nonlinear exposure - response association between trimester exposure of PM 2.5 and adjusted RR (95\% Cl) for HDP. The histogram at the bottom shows the relative overall distribution of $\mathrm{PM}_{2.5}$ concentrations in the different period. The rug plot shows the amount of women according the $\mathrm{PM}_{2.5}$ concentration

Table 3 Association of $\mathrm{PM}_{2.5}$ and HDP by gestational periods

\begin{tabular}{|c|c|c|c|c|c|}
\hline & No. of cases & $(\%)$ & Crude RR $(95 \% \mathrm{Cl})$ & Adjusted RR $(95 \% \mathrm{Cl})$ & $P$ for trend \\
\hline \multicolumn{6}{|c|}{$0-12$ gestational weeks } \\
\hline Continuous & 440 & 5.1 & $4.03(2.11-7.72)$ & $3.89(1.45-10.43)$ & \\
\hline Q1 (< 46.36) & 76 & 3.5 & Reference (1.00) & Reference (1.00) & \\
\hline Q2 (46.36-54.54) & 103 & 4.7 & $1.33(0.99-1.79)$ & $1.30(0.93-1.82)$ & \\
\hline Q3 (54.54-60.06) & 129 & 5.9 & $1.67(1.26-2.22)$ & $1.66(1.11-2.48)$ & \\
\hline Q4 ( $\geq 60.06)$ & 132 & 6.0 & $1.70(1.28-2.26)$ & $1.67(1.10-2.53)$ & $<0.01$ \\
\hline \multicolumn{6}{|c|}{ 13-20 gestational weeks } \\
\hline Continuous & 440 & 5.0 & $1.11(0.66-1.87)$ & $0.71(0.40-1.27)$ & \\
\hline Q1 $(<44.41)$ & 113 & 5.1 & Reference (1.00) & Reference (1.00) & \\
\hline Q2 (44.41-52.03) & 105 & 4.8 & $0.93(0.71-1.21)$ & $0.85(0.65-1.12)$ & \\
\hline Q3 (52.03-56.35) & 109 & 5.0 & $0.98(0.75-1.27)$ & $0.88(0.67-1.15)$ & \\
\hline Q4 ( $\geq 56.35)$ & 113 & 5.2 & $1.02(0.78-1.32)$ & $0.85(0.64-1.12)$ & 0.82 \\
\hline \multicolumn{6}{|c|}{ 0-20 gestational weeks } \\
\hline Continuous & 440 & 5.0 & $2.22(1.05-4.68)$ & $1.00(0.38-2.61)$ & \\
\hline Q1 $(<47.35)$ & 97 & 4.4 & Reference (1.00) & Reference (1.00) & \\
\hline Q2 (47.35-51.42) & 103 & 4.7 & $1.06(0.80-1.40)$ & $0.90(0.67-1.23)$ & \\
\hline Q3 (51.42-57.81) & 111 & 5.1 & $1.14(0.87-1.50)$ & $0.89(0.65-1.24)$ & \\
\hline Q4 ( $\geq 57.81)$ & 129 & 5.9 & $1.33(1.03-1.74)$ & $1.01(0.73-1.41)$ & 0.02 \\
\hline
\end{tabular}


Table 4 Interaction of covariates and PM2.5 exposure during first trimester with the risk of HDP

\begin{tabular}{lll}
\hline Covariates & \multicolumn{1}{c}{$\begin{array}{c}\text { Multiplicative scale } \\
\text { RR (95\% Cl) }\end{array}$} & $\begin{array}{c}\text { Additive scale } \\
\text { RERI (95\% Cl) }\end{array}$ \\
\hline Maternal age ( $\geq 35$ years) & $0.61(0.33-1.15)$ & $0.32(-0.18-0.81)$ \\
Parity (Nulliparous) & $2.28(1.28-4.06)$ & $0.92(0.46-1.38)$ \\
Parental history of chronical diseases (Yes) & $1.04(0.69-1.55)$ & $0.20(-1.22-1.62)$ \\
Season of conception (Spring or winter) & $0.89(0.31-1.92)$ & $-0.09(-1.62-1.44)$ \\
Pre-conception BMI (Underweight) & $2.03(0.93-4.46)$ & $0.42(-0.10-0.93)$ \\
Pre-conception BMI (Overweight or obesity) & $1.24(0.81-1.87)$ & $0.26(-0.47-0.99)$ \\
\hline
\end{tabular}

${ }^{\mathrm{a}} \mathrm{RERI}=0$ : indicates no interaction. $\mathrm{RERI}<0$ : indicates negative interaction or less than additive interaction. RERI $>0$ : indicates positive interaction or more than additive interaction

exposure to high levels of $\mathrm{PM}_{2.5}$ during early pregnancy was associated with increased prevalence of HDP [12]. Actually, the concentration of the $\mathrm{PM}_{2.5}$ in their study (median $=9.5 \mu \mathrm{g} \mathrm{m}^{-3}$ ) is still much lower than the concentration in the present study (median $=54.1 \mathrm{\mu g} \mathrm{m}^{-3}$ ); and the risk of HDP increased by $43 \%$ (from 24 to $67 \%$ ) as per IQR increase of $\mathrm{PM}_{2.5}$ concentration. While another study, linking birth certificates and Community Air Survey data in New York city, did not provide clear evidence of an effect of ambient air pollution on HDP [10]. The author also stated that their results might be bias to the null due to the uncertain impact of adjusting for delivery hospital. In addition, the different models for estimating exposure made the data incomparable.

Although air quality in Shanghai is better than other large cities in China and the government has taken strategy to control air pollution since 2013 [30], the level of $\mathrm{PM}_{2.5}$ in this study was still higher than reported in previous studies performed in other countries. Dadvand et al. used LUR model to predict the $\mathrm{PM}_{2.5}$ concentration in 8398 women and reported that first and third trimester exposure to $\mathrm{PM}_{2.5}$ is associated with the risk of preeclampsia [31]. Mobasher et al. also reported a positive association between $\mathrm{PM}_{2.5}$ exposure and HDP during the first trimester and throughout pregnancy [16]. These findings are consistent with our results on the elevated risk of HDP following $\mathrm{PM}_{2.5}$ exposure in the first trimester. The average $\mathrm{PM}_{2.5}$ concentrations reported in their studies (16.5 and $18.1 \mu \mathrm{g} \mathrm{m}^{-3}$, respectively) are much lower than the concentration recorded in our study $\left(51.4 \mu \mathrm{g} \mathrm{m}^{-3}\right)$.

Few studies have tested the interaction effect of demographic characteristics and $\mathrm{PM}_{2.5}$ exposure on the HDP. According to Mobasher et al., the association between $\mathrm{PM}_{2.5}$ and HDP is modified by BMI. Kannan et al. also reported a positive association between $\mathrm{PM}_{2.5}$ exposure and increased pulse pressure for participants categorized as obese (BMI $\geq 30 \mathrm{~kg} \mathrm{~m}^{-2}$ ) [32]. Due to the ethnic differences between American women and Asian women, the criteria used to establish BMI categories and the prevalence for overweight or obesity are different in the two studies. We identified a modifying effect of parity instead of pre-conception BMI. The association is more obvious for the nulliparous women. The childbearing policy also leads to a different distribution in parity among western countries and China. Specifically, more nulliparous women were included in our study $(81 \%$ vs. $56 \%$ ). A previous study performed among AsianAmerican women showed that nulliparity is significantly associated with gestational hypertension [33]. Another study involving 49 hospitals in Canada also reported that a history of term pregnancy conveys a substantial "protection" against preeclampsia [34]. Given the high proportion of nullipara in our study, further studies are needed to confirm our findings on parity.

The potential mechanisms underlying the associations between $\mathrm{PM}_{2.5}$ exposure and HDP remain unclear. However, first trimester trophoblast cells that are exposed to $\mathrm{PM}_{2.5}$ respond with reduced growth, oxidative stress, inflammation and endoplasmic reticulum stress [35, 36]. In addition, an animal study observed the induction of a persistent intrauterine inflammatory state following $\mathrm{PM}_{2.5}$ exposure, and the greatest effect was observed for the first trimester exposure [37]. Histopathological changes and vascular injuries of the placenta were also observed in mice exposed to $\mathrm{PM}_{2.5}$ [38]. All these changes were reported to underlie the pathogenesis of HDP [39].

To our knowledge, this study represents the first attempt to estimate the association between exposure to high concentrations of $\mathrm{PM}_{2.5}$ and its interaction with demographic characteristics with HDP in the Chinese population, which consolidated the evidence on the association of $\mathrm{PM}_{2.5}$ with hypertension. While some limitations should also be noted. First, although the baseline characteristics are comparable between the included women and excluded women, selection bias cannot be ruled out and further study is needed to consolidate the findings in our study. In addition, single geographic region of Shanghai limits the generalizability of our finds. Second, the exact blood pressure and diagnosis date of HDP were unavailable, which might result in exposure misclassification. Women with higher exposure during 
the late second trimester but not in the first trimester would be classified as unexposed and bias the result towards the null. Meanwhile, the estimates were robust when we included or excluded the $\mathrm{PM}_{2.5}$ exposure in the late period of the second trimester (20-28 gestational weeks, data available upon request). Third, the deidentified electronic medical system does not have data on lifestyle factors (maternal smoking, alcohol use), diet, and other potential risk factors for HDP that might induce residual confounding. Although smoking might be a strong effect modified factor in this study, the proportion of active smoking is rare among Chinese pregnant women. Meanwhile, the passive smoking rate of pregnant women also sharply decreased to $7.8 \%$ consequently since public places smoking control regulations issued in 2010 [40]. Our data also suggested that the included women were more likely to have governmentsponsored health care insurance, indicating a higher social status, less likely to be a smoker, and more likely to lead a healthy lifestyle. Hence, adjusting for health insurance in the regression model partly reduced the confounding related to the lifestyle. Furthermore, a case-control study of approximately 2500 births in Los Angeles County indicated that associations between air pollution and preterm birth were insensitive to adjustment for occupation or income [41]. Finally, although our cohort was compiled during 2014-2015 in a single institute and no change of definition of HDP were warrants, the lack of specific diagnosis might result in misclassification of HDP. We believe that the misclassification is nondifferential as it is unlikely to be related the $\mathrm{PM}_{2.5}$ exposure, thus bias the estimates towards the null again.

\section{Conclusion}

In conclusion, exposure to $\mathrm{PM}_{2.5}$ during the first trimester tends to be associated with an increased risk of HDP. The effect estimates are more obvious for nulliparous women than multiparous women. Our findings suggested that the concentration of $\mathrm{PM}_{2.5}$ is still high in Shanghai, China. There is a need for better and sustainable air pollution control in order to reduce the disease burden of HDP among pregnant women, especially for nulliparous women.

\section{Supplementary information}

Supplementary information accompanies this paper at https://doi.org/10. 1186/s12940-020-00655-1.

Additional file 1: Table S1. Comparison of basic characteristic between included and excluded women.

\section{Abbreviations}

$\mathrm{PM}_{2.5}$ : Fine particulate matter; HDP: Hypertensive disorders of pregnancy; IQR: Interquartile range; BMI: Body mass index; LUR: Land-use regression; SD: Standard deviations; RR: Relative risk; Cl: Confidence interval

\section{Acknowledgements}

Not applicable.

\section{Authors' contributions}

XJS wrote original draft. YZ made a substantial contribution in study design and methodology. YYY interpreted the data and edited the draft. Jing Hua is was a major contributor in validating of the dataset. All authors read and approved the final manuscript.

\section{Funding}

Xiujuan Su was supported by the National Natural Science Foundation of China (grant number 81602860) and Key Laboratory of Public Health Safety (Fudan University), Ministry of Education, China (grant number GW2019-10). Yingying Yang was supported by the Shanghai Municipal Commission of Health and Family Planning (grant number 20174Y0010).

\section{Availability of data and materials}

The data that support the findings of this study are available from Shanghai First maternity and Infant hospital but restrictions apply to the availability of these data, which were used under license for the current study, and so are not publicly available. Data are however available from the authors upon reasonable request and with permission of Shanghai First maternity and Infant hospital.

\section{Ethics approval and consent to participate}

The study was approved by the Ethics Committee of Shanghai First Maternity and Infant Hospital, Tongji University School of Medicine. The study was performed in accordance with the approved guidelines, and all participants provided written informed consent before enrollment.

Consent for publication

Not applicable.

\section{Competing interests}

The authors declare that they have no competing interests.

Received: 28 April 2020 Accepted: 11 September 2020

Published online: 17 September 2020

\section{References}

1. Hammad IA, Meeks H, Fraser A, Theilen LH, Esplin MS, Smith KR, et al. Risks of cause-specific mortality in offspring of pregnancies complicated by hypertensive disease of pregnancy. Am J Obstet Gynecol. 2019;222(1):75.

2. Robledo CA, Mendola P, Yeung E, Mannisto T, Sundaram R, Liu D, et al. Preconception and early pregnancy air pollution exposures and risk of gestational diabetes mellitus. Environ Res. 2015;137:316-22.

3. Lain KY, Roberts JM. Contemporary concepts of the pathogenesis and management of preeclampsia. JAMA. 2002;287(24):3183-6.

4. Wang IK, Chang SN, Liao CC, Liang CC, Chang CT, Lin HH, et al. Hypertensive disorders in pregnancy and preterm delivery and subsequent stroke in Asian women: a retrospective cohort study. Stroke. 2011;42(3):71621

5. Feng XL, Zhu J, Zhang L, Song L, Hipgrave D, Guo S, et al. Socio-economic disparities in maternal mortality in China between 1996 and 2006. Bjog-Int J Obstet Gy. 2010;117(12):1527-36.

6. Lin H, Guo Y, Zheng Y, Di Q, Liu T, Xiao J, et al. Long-term effects of ambient PM2.5 on hypertension and blood pressure and attributable risk among older Chinese adults. Hypertension. 2017;69(5):806-12.

7. Yang BY, Guo Y, Bloom MS, Xiao X, Qian ZM, Liu E, et al. Ambient PM1 air pollution, blood pressure, and hypertension: insights from the 33 communities Chinese health study. Environ Res. 2019;170:252-9.

8. Zhang Z, Guo C, Lau AKH, Chan TC, Chuang YC, Lin C, et al. Long-term exposure to fine particulate matter, blood pressure, and incident hypertension in Taiwanese adults. Environ Health Perspect. 2018;126(1): 017008

9. Brook RD, Rajagopalan S, Pope CA 3rd, Brook JR, Bhatnagar A, Diez-Roux AV, et al. Particulate matter air pollution and cardiovascular disease: an update to the scientific statement from the American Heart Association. Circulation. 2010;121(21):2331-78. 
10. Savitz DA, Elston B, Bobb JF, Clougherty JE, Dominici F, Ito K, et al. Ambient fine particulate matter, nitrogen dioxide, and hypertensive disorders of pregnancy in New York City. Epidemiology. 2015;26(5):748-57.

11. Mendola P, Wallace M, Liu D, Robledo C, Mnnist T, Grantz KL. Air pollution exposure and preeclampsia among US women with and without asthma. Environ Res. 2016;148:248-55.

12. $\mathrm{Xu} \mathrm{X}, \mathrm{Hu} \mathrm{H}, \mathrm{Ha} \mathrm{S}$, Roth J. Ambient air pollution and hypertensive disorder of pregnancy. J Epidemiol Community Health. 2014;68(1):13-20.

13. Vinikoor-Imler LC, Gray SC, Edwards SE, Miranda ML. The effects of exposure to particulate matter and neighbourhood deprivation on gestational hypertension. Paediatr Perinat Epidemiol. 2012;26(2):91-100.

14. Hu H, Ha S, Roth J, Kearney G, Talbott EO, Xu X. Ambient air pollution and hypertensive disorders of pregnancy: a systematic review and meta-analysis. Atmos Environ (1994). 2014;97:336-45.

15. Pedersen M, Stayner L, Slama R, Sorensen M, Figueras F, Nieuwenhuijsen MJ, et al. Ambient air pollution and pregnancy-induced hypertensive disorders: a systematic review and meta-analysis. Hypertension. 2014;64(3): 494-500.

16. Mobasher Z, Salam MT, Goodwin TM, Lurmann F, Ingles SA, Wilson ML. Associations between ambient air pollution and hypertensive disorders of pregnancy. Environ Res. 2013;123:9-16.

17. Nobles CJ, Williams A, Ouidir M, Sherman S, Mendola P. Differential effect of ambient air pollution exposure on risk of gestational hypertension and preeclampsia. Hypertension. 2019;74(2):384-90.

18. Organization WH. WHO air quality quidelines for particulate matter, ozone, nitrogen dioxide and sulfur dioxide; 2005. p. 9-11.

19. Su X, Zhao Y, Cao Z, Yang Y, Duan T, Hua J. Association between isolated hypothyroxinaemia in early pregnancy and perinatal outcomes. Endocr Connect. 2019;8(4):435.

20. Consultation WHOE. Appropriate body-mass index for Asian populations and its implications for policy and intervention strategies. Lancet. 2004; 363(9403):157-63.

21. Liu C, Henderson BH, Wang D, Yang X, Peng ZR. A land use regression application into assessing spatial variation of intra-urban fine particulate matter (PM2.5) and nitrogen dioxide (NO2) concentrations in City of Shanghai, China. Sci Total Environ. 2016:565:607-15.

22. Ross Z, Jerrett M, Ito K, Tempalski B, Thurston GD. A land use regression for predicting fine particulate matter concentrations in the New York City region. Atmos Environ. 2007:41(11):2255-69.

23. Zhao Y, Cao Z, Li H, Su X, Yang Y, Liu C, et al. Air pollution exposure in association with maternal thyroid function during early pregnancy. J Hazard Mater. 2018;367:188-93.

24. Baumgartner J, Schauer JJ, Ezzati M, Lu L, Cheng C, Patz JA, et al. Indoor air pollution and blood pressure in adult women living in rural China. Environ Health Perspect. 2011;119(10):1390-5.

25. Durrleman S, Simon R. Flexible regression models with cubic splines. Stat Med. 1989;8(5):551-61.

26. Savitz DA, Bobb JF, Carr JL, Clougherty JE, Dominici F, Elston B, et al. Ambient fine particulate matter, nitrogen dioxide, and term birth weight in New York, New York. Am J Epidemiol. 2014;179(4):457-66.

27. Nobles CJ, Grantz KL, Liu D, Williams A, Ouidir M, Seeni I, et al. Ambient air pollution and fetal growth restriction: physician diagnosis of fetal growth restriction versus population-based small-for-gestational age. Sci Total Environ. 2019;650(Pt 2):2641-7.

28. Andersson T, Alfredsson L, Kallberg H, Zdravkovic S, Ahlbom A. Calculating measures of biological interaction. Eur J Epidemiol. 2005;20(7):575-9.

29. Hu J, Li Y, Zhang B, Zheng T, Li J, Peng Y, et al. Impact of the 2017 ACC/ AHA guideline for high blood pressure on evaluating gestational hypertension-associated risks for newborns and mothers. Circ Res. 2019: 125(2):184-94.

30. Chen Z, Wang JN, Ma GX, Zhang YS. China tackles the health effects of air pollution. Lancet. 2013;382(9909):1959-60.

31. Dadvand P, Figueras F, Basagana X, Beelen R, Martinez D, Cirach M, et al Ambient air pollution and preeclampsia: a spatiotemporal analysis. Environ Health Perspect. 2013;121(11-12):1365-71.

32. Kannan S, Dvonch JT, Schulz AJ, Israel BA, Mentz G, House J, et al. Exposure to fine particulate matter and acute effects on blood pressure: effect modification by measures of obesity and location. J Epidemiol Community Health. 2010;64(1):68-74
33. Li C, Binongo JN, Kancherla V. Effect of parity on pregnancy-associated hypertension among Asian American women in the United States. Matern Child Health J. 2019;23(8):1098-107.

34. Xiong $X$, Fraser WD, Demianczuk NN. History of abortion, preterm, term birth, and risk of preeclampsia: a population-based study. Am J Obstet Gynecol. 2002;187(4):1013-8.

35. Familari M, Naav A, Erlandsson L, de longh RU, Isaxon C, Strandberg B, et al. Exposure of trophoblast cells to fine particulate matter air pollution leads to growth inhibition, inflammation and ER stress. PLoS One. 2019;14(7): e0218799.

36. Liu Y, Wang L, Wang F, Li C. Effect of fine particulate matter (PM2.5) on rat placenta pathology and perinatal outcomes. Med Sci Monit. 2016;22:327480.

37. Nachman RM, Mao G, Zhang X, Hong X, Chen Z, Soria CS, et al. Intrauterine inflammation and maternal exposure to ambient PM2.5 during preconception and specific periods of pregnancy: the Boston birth cohort. Environ Health Perspect. 2016:124(10):1608-15.

38. Yue H, Ji X, Zhang Y, Li G, Sang N. Gestational exposure to PM2.5 impairs vascularization of the placenta. Sci Total Environ. 2019;665:153-61.

39. Phipps E, Prasanna D, Brima W, Jim B. Preeclampsia: updates in pathogenesis, definitions, and guidelines. Clin J Am Soc Nephrol. 2016;11(6): 1102-13.

40. Shi L, Dong Y, Pei S, Cai Y, Huang H. Passive smoking status and its influencing factors among pregnant women in Shanghai. J Shanghai Jiaotong Univ (Medical Science). 2017;37(2):141.

41. Ritz B, Wilhelm M, Hoggatt KJ, Ghosh JK. Ambient air pollution and preterm birth in the environment and pregnancy outcomes study at the University of California, los Angeles. Am J Epidemiol. 2007;166(9):1045-52.

\section{Publisher's Note}

Springer Nature remains neutral with regard to jurisdictional claims in published maps and institutional affiliations.

Ready to submit your research? Choose BMC and benefit from:

- fast, convenient online submission

- thorough peer review by experienced researchers in your field

- rapid publication on acceptance

- support for research data, including large and complex data types

- gold Open Access which fosters wider collaboration and increased citations

- maximum visibility for your research: over $100 \mathrm{M}$ website views per year

At $\mathrm{BMC}$, research is always in progress.

Learn more biomedcentral.com/submissions 